\title{
BULLETIN
}

\section{INTER NAT I0 NAL}

DES

SOCIÉTÉS DE LA CROIX-ROUGE

PUBLIÉ PAR LB

COMITÉ INTERNATIONAI

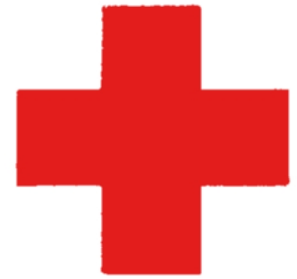

$W_{T_{R}}$ aRMA CARU

GENÈVE

IMPRIMERIE I. SOULLIER, GITÉ, 19-21

JANVIFR 1897 


\section{COMITÉ INTERÑATIONAL}

Pour adresse : M. Gustave Moynuer, Président. En hiver : rue de l'Athénée, 8 , a Genève; en été : a Sécheron, près Genève.

Les membres du Comité sont:

MM. Moynier, Gustave, Président d'honneur de l'Institut de droit international, Correspondant de I'Institut de France, Président.

Ador, Gustave, Conseiller d'État, Vice-Président.

Odier, Fdouard, Avocat, Secrétaire.

Appia, Louis, Dr méd.

D'Espine, Adolphe, Dr méd., professeur à l'Université.

Favre, Camille, Colonel brigadier.

Ferrière, Frédéric, Dr-méd.

Gautier, Alfred, Profẹsseur à l'Université et juge à la Cour de cassation.

\section{ADRESSES DES COMITES GENTRAUX}

ALLEMAGNE. - Comité central des associations allemandes de la Croix-Rouge. Wilhelmstrasse, 73, à Berlin.

ARgentine (RÉpublique). - M. le $\mathrm{D}^{\mathrm{r}}$ Pedro F. Roberts, président, pour la Société argentine de la Croix-Rouge, Victoria 723, à Buenos-Ayres.

AUTRICHE: - Société autrichienne de la Croix-Rouge. Herrengasse, 23, à Vienne.

BADE. - Comité général de la Société badoise de la GroixRouge. Gartenstrasse, 47, à Carlsruhe.

BAVIÈRE. - M. le Comte DE Drechsel, président du Comité central de la Société bavaroise pour le soin des militaires blessés et malades en campagne, à Munich.

BELGIQUE. - M. le Dr Mullier, vice-président de la Société belge de la Croix-Rouge, rue Rogier, 303, à Bruxelles.

BULGaRIE. - M. le $\mathrm{D}^{\mathrm{r}}$ Jetcheff, président de la Société bulgare de la Croix-Rouge, à Sofia.

CONGo. - Association congolaise et africaine de la CroixRouge, rue de Namur, 12, à Bruxelles.

DANEMARK - Société de la Croix-Rouge (Det Rode Kors), à Copenhague $K$.

ESPAGNE. - Société espagnole de la Croix-Rouge, Isabel la Catolica, 4 duplicado, pral. Madrid.

ÉTATS-UNiS: - Miss Clara Barton, présidente, pour la Société américaine de la Croix-Rouge, à Washington.

FRANCE. - Société française de secours aux militaires blessés des armées de terre et de mer. Rue Matignon, 19, à Paris.

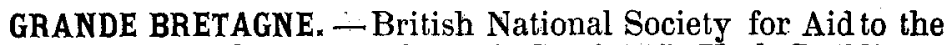
Sıck and Wounded in war. Central Comité. 5, York Buildings, Adelphi, London.

(Yoir la suite à la troisième page de cette couverture) 


\section{BULLETIN INTERNATIONAL}

DE LA

\section{CROIX-ROUGE}

VINGT-EIUIIIÈME ANNÉE 


\section{BULLETIN}

\section{INTER NATIONAL \\ DES}

SOCIÉTÉS DE LA GROIX-ROUGE

PUBLIE PAR LB

COMITE INTERNATIONAI

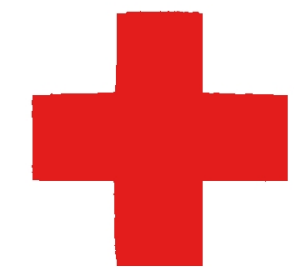

"W

\section{GENEVE}

IMPRIMERIE 1. SOULLIER, CITÉ, 19-21

\section{7}

